\title{
Towards a Sustainable Energy Balance: Progressive Efficiency and the Return of Energy Conservation
}

\author{
Jeffrey Harris, Rick Diamond, Maithili Iyer, Christopher Payne, Carl Blumstein, Hans-
} Paul Siderius

\begin{abstract}
We argue that a primary focus on energy efficiency may not be sufficient to slow (and ultimately reverse) the growth in total energy consumption and carbon emissions. Instead, policy makers need to return to an earlier emphasis on "conservation," with energy efficiency seen as a means rather than an end in itself. We briefly review the concept of "intensive" versus "extensive" variables (i.e., energy efficiency versus energy consumption), and why attention to both consumption and efficiency is essential for effective policy in a carbon- and oil-constrained world with increasingly brittle energy markets. To start, energy indicators and policy evaluation metrics need to reflect energy consumption as well as efficiency.

We introduce the concept of "progressive efficiency," with the expected or required level of efficiency varying as a function of house size, appliance capacity, or more generally, the scale of energy services. We propose introducing progressive efficiency criteria first in consumer information programs (including appliance labeling categories) and then in voluntary rating and recognition programs such as ENERGY STAR. As acceptance grows, the concept could be extended to utility rebates, tax incentives, and ultimately to mandatory codes and standards.

For these and other programs, incorporating criteria for consumption as well as efficiency offers a path for energy experts, policy-makers, and the public to begin building consensus on energy policies that recognize the limits of resources and global carrying-capacity. Ultimately, it is both necessary and, we believe, possible to manage energy consumption, not just efficiency in order to achieve a sustainable energy balance. Along the way, we may find it possible to shift expectations away from perpetual growth and toward satisfaction with sufficiency.
\end{abstract}

Key words: appliances, buildings, energy consumption, energy conservation, energy efficiency, energy sufficiency, progressive efficiency 


\section{An Overview of Energy Efficiency and Energy Consumption}

\subsection{Energy Efficiency Is Not Enough}

For the past quarter century, the energy efficiency community has worked hard to focus on energy efficiency or productivity (more services per unit of energy) and to sharply distinguish its goals from "conserving," or using less energy. The latter implied doing without the energy services presumed to be essential for modern life - or at least presumed to be our inalienable right. A few voices have challenged this assumption, arguing that energy consumption does matter and that energy efficiency is one way - perhaps not the only way - to reduce energy use (Rudin 2000; Wilhite et al. 2000; Wilhite and Norgard, 2004; Moezzi and Diamond 2005; Siderius 2004). Meanwhile, headlines about climate change, peak oil, event-triggered fuel or electricity shortages and price spikes, and air pollution all send the message that energy consumption, not just energy efficiency, does matter. These new realities also begin to call into question our unconstrained appetite for energy services and our future ability to afford them.

Thirty years ago President Jimmy Carter called for sweaters and sacrifice, and the energy efficiency community caught a cold - afraid of popular backlash against conservation as sacrifice. Today we might instead ask why a sweater (or in summer a short-sleeve shirt to replace coat and tie) should not be one way to satisfy our desires for comfort while using less energy. Energy efficiency has made an enormous contribution over the years, reducing growth in energy demand well below what it otherwise might have been. But this has not been enough - in the U.S. and other industrial countries, and even more strikingly in rapidly developing economies like China and India - to offset the forces driving increased energy consumption: population growth, increased wealth and income, and our collective preferences for ever larger and more energy-intensive products and services.

Despite notable gains in the energy efficiency of building envelopes, lighting, heating, ventilating and air conditioning (HVAC), and plug loads, total primary energy use has increased over 30\% in U.S. residential buildings since 1978 and more than 65\% in commercial buildings (Figure 1). The growth in buildings sector energy has been significantly faster than for all U.S. energy (25\%). Of course, there are many ways to "explain" (i.e., disaggregate) this growth in energy use in the U.S.: growth in building floor space, population shifts to the south along with increasing penetration of central air conditioning, growing saturation of appliances and miscellaneous loads (especially consumer and office electronics with their continuous standby energy), and consumers' desire and ability to pay for thermal comfort and conditioned fresh air. Since most of these growing energy services rely on electricity, the trends need to be tracked in terms of primary (resource) energy rather than site (delivered) energy (i.e., including electricity system losses). Tracking primary energy, not site energy, is all the more important when our energy concerns include resource depletion, carbon emissions, and affordability. 
Figure 1. Primary Energy Use in U.S. Buildings, 1978-2004

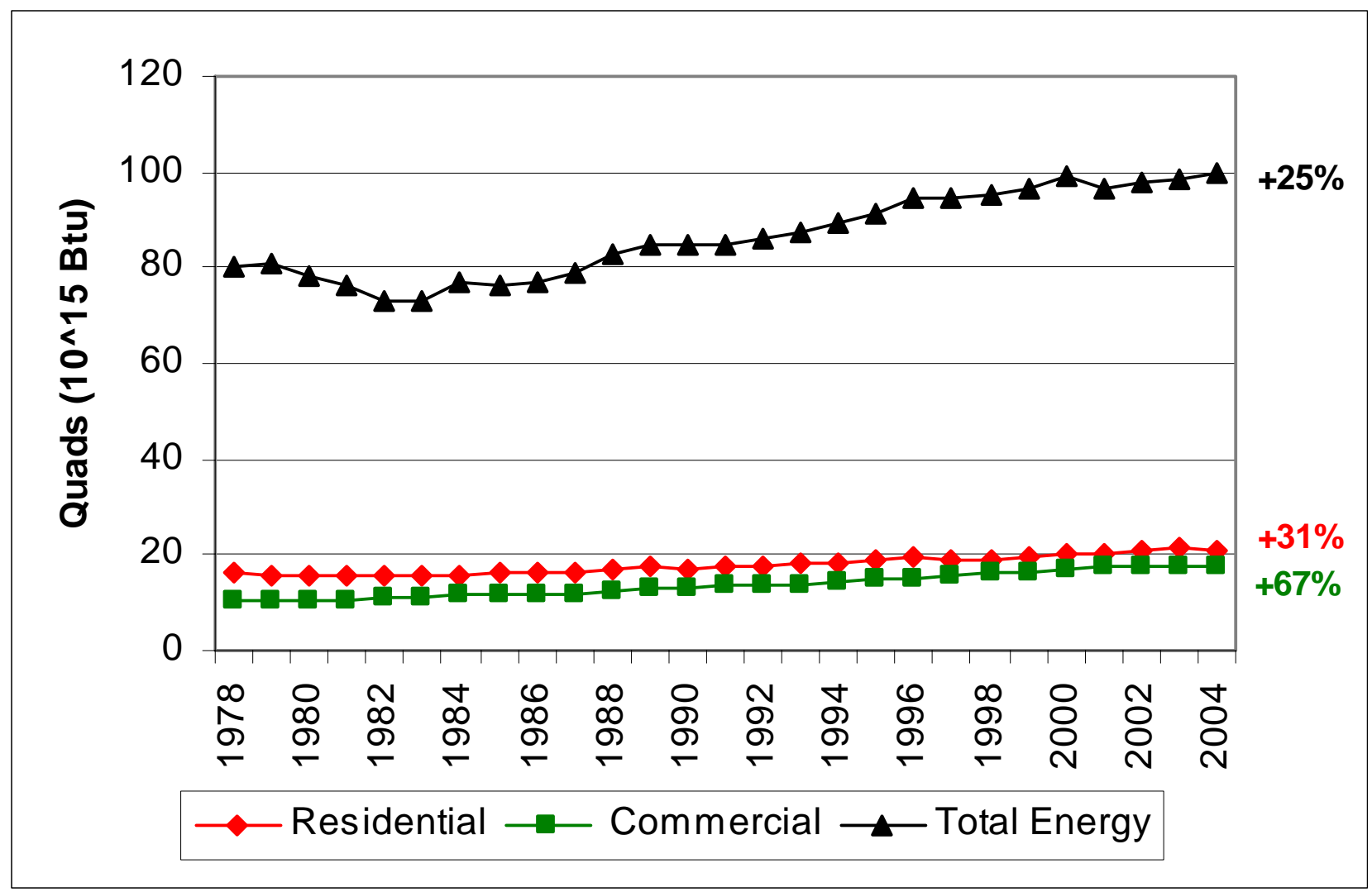

Source: EIA 2004a

An energy policy that seeks to mitigate climate change, avoid pollution, and/or reduce oil dependency must measure its success in terms of lower fossil fuel energy consumption - or at least slower growth in consumption. At present, there is ambiguity about the main thrust of energy-saving policies at both national and state levels. In some cases the focus remains strictly on efficiency without regard to consumption; in others consumption-management ("conservation") is creeping in, especially where the policy drivers include oil dependence, electric grid capacity and reliability, climate change, air pollution, or water consumption for cooling power plants. And in many cases policy-makers seem confused, or deliberately vague, about efficiency versus conservation, perhaps in the hope that efficiency improvements will be powerful enough to reduce absolute energy use and carbon - without any constraint on consumers or consumption.

Some observers have suggested that energy efficiency itself can lead to increased consumption, by lowering the cost of energy services (Binswinger 2001, Howarth 1997, and Birol and Keppler 2000). Others maintain that a pre-occupation with energy-saving hardware leads us to overlook non-hardware behavioral changes that may both improve the efficient operation of buildings and equipment, and in some cases, reduce the demand for energy services (Herring 2006). The purpose of this paper is not to further debate the "snapback" effect of 
efficiency on energy consumption nor the merits of technology versus behavior change. Nor do we anticipate or advocate an imminent mass movement toward "voluntary simplicity" welcome though that might be to help ease any number of environmental problems.

Rather than discard energy efficiency, we seek to enhance it, by (re-) introducing energy conservation as a legitimate and desirable policy goal, and by drawing attention to trends in energy consumption as well as energy efficiency. Framing policy goals in terms of energy consumption rather than energy efficiency can help us decide how much efficiency is needed, and how much additional "conserving" may be required to manage energy consumption and emissions in the face of unsaturated markets, growing population, disposable incomes, and consumer desires.

\subsection{Sustainable Energy Balance as the Goal of Energy Policy}

Efficiency and conservation, even in combination, offer only a partial solution to the problems of limited utility system capacity, fossil fuel resources, and climate change. Renewable sources of energy supply must also be part of the equation, an equation that becomes much easier to balance when demand growth is under control. Several examples in this paper show that efficiency alone cannot control energy consumption. On the other hand, energy conservation may not be satisfactory as a policy goal if it only provides a direction, and not an unambiguous target, e.g., net zero fossil energy consumption. Efficiency and conservation can both be framed within the broader concept of a sustainable energy balance, where energy consumption equals sustainable energy production. A sustainable level of energy consumption and production is climate neutral, i.e., no net greenhouse gas emissions, and does not use up finite, stored energy resources. This concept introduces an additional degree of freedom to specify energy and environmental policy goals: As long as sustainable production matches energy consumption there is no need to cut consumption. In other words, the sustainable energy balance serves as a goal for which energy conservation and energy efficiency, along with renewable energy supply, are the means. Ultimately, the sustainable energy balance would mean a renewable energy only economy. But this is a future goal, a framework to work towards, and this paper tries to show some first steps on this way, to shape our thinking towards the goal of a sustainable energy balance. Figure 2 shows how these concepts are related. 
Figure 2. Sustainable Energy Balance

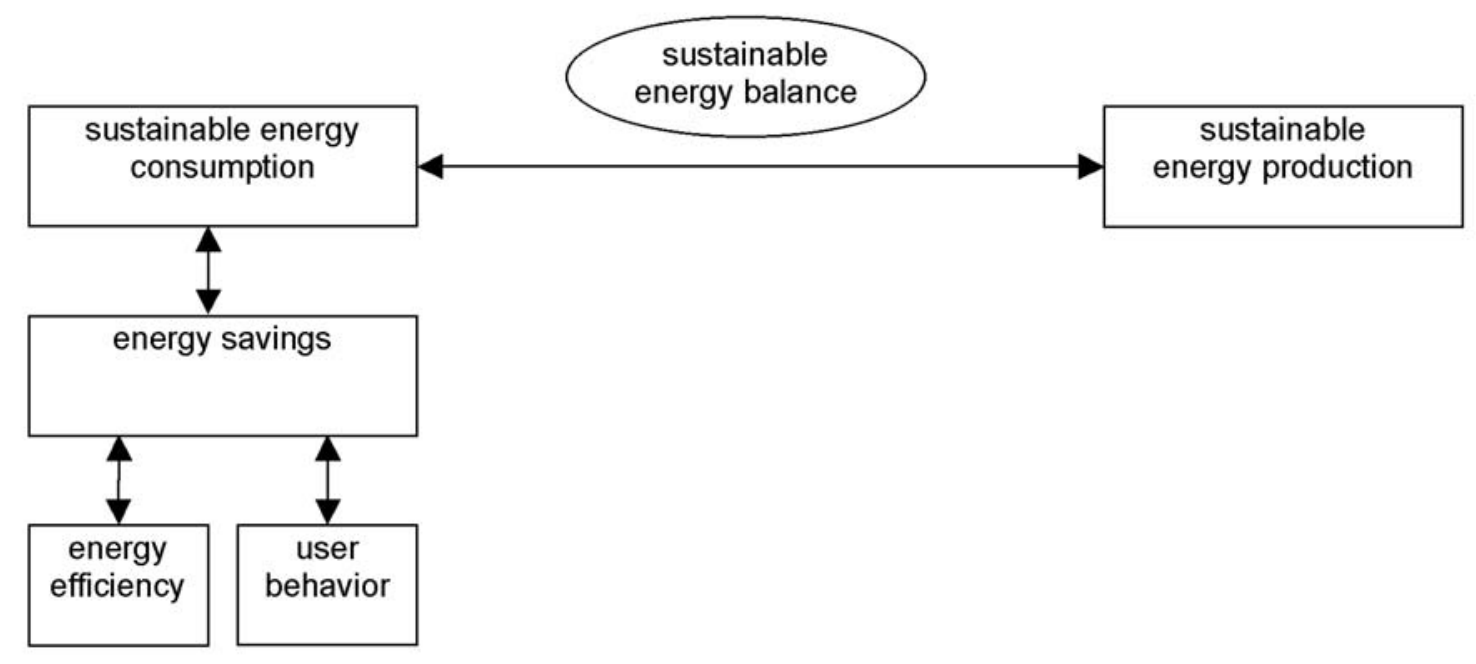

The relationships in Figure 2 can be read from two sides. The left side, a bottom-up approach, shows what contribution energy efficiency and user behavior provide to energy savings and lower energy consumption. This provides a target for the amount of energy that must be matched by sustainable production to reach the sustainable energy balance. The right side, or top-down approach gives an estimate of the sustainable production capacity, and gives insight into the corresponding energy consumption. Comparing this value with current consumption levels indicates the targets for energy savings and improvements in energy efficiency and/or user behavior. In this paper we will focus on the left-hand side of Figure 2, the sustainable demand for energy services, and in particular, the role of energy efficiency.

\subsection{The Concept of Progressive Efficiency}

We recognize that it may be impractical today to propose a quantum leap from a policy of pursuing all economically justified energy efficiency to a broader policy framework based on a sustainable energy balance. Instead, this paper outlines some initial steps toward the goal of managing total energy consumption, with efficiency as a means to that goal. The central idea, which we term "progressive efficiency," is that the level of energy efficiency, rather than remain constant, should increase as the scale of energy use or energy service increases, i.e., with larger appliances, homes, or vehicles. This concept is also known as "variable" efficiency (Meier, 2000). In some cases, physics alone would dictate increased efficiency with scale: surface-tovolume ratios suggest that a larger building envelope, larger refrigerator, or larger water heater tank should have proportionately lower thermal losses or gains. In practice, though, efficiency criteria for large units are sometimes less stringent rather than equally or more stringent. The four sketches in Figure 3 illustrate schematically the current approach to energy efficiency (Cases 1 and 2), and our alternative formulation of progressive efficiency (Case 3). At the limit (Case 4), this concept of progressive efficiency becomes a criterion of "sufficiency" (Princen 2005). 
Figure 3. Efficiency Varying with Scale

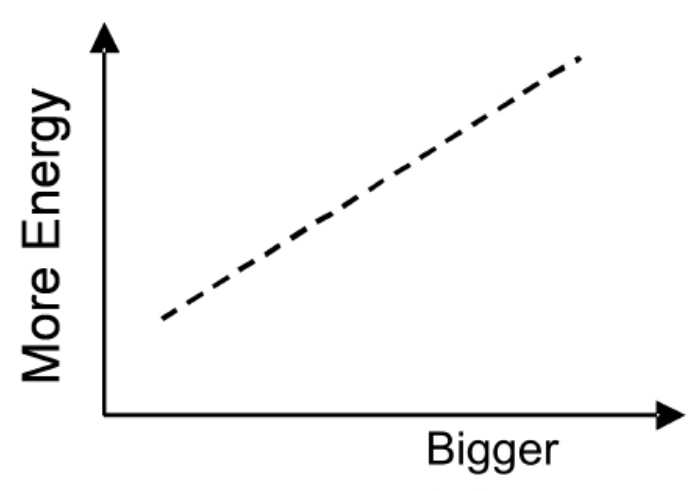

Case 1: Linear Efficiency

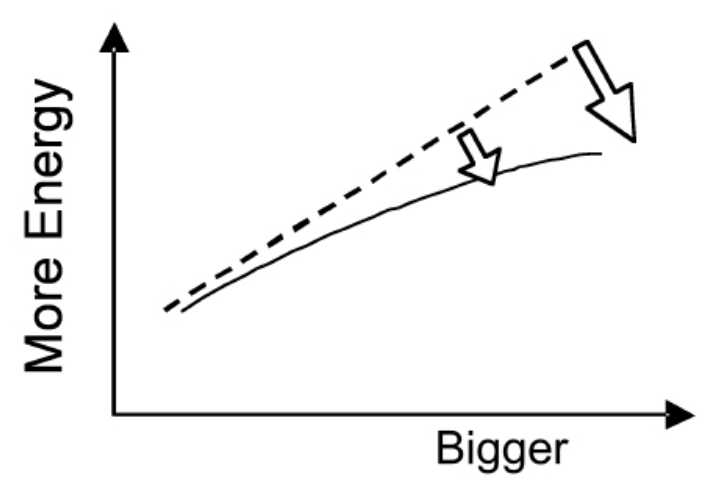

Case 3: Variable Efficiency

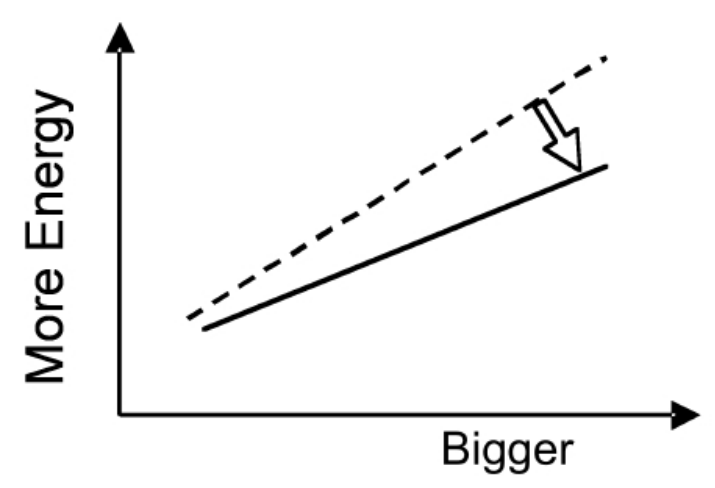

Case 2: Improved (Linear) Efficiency

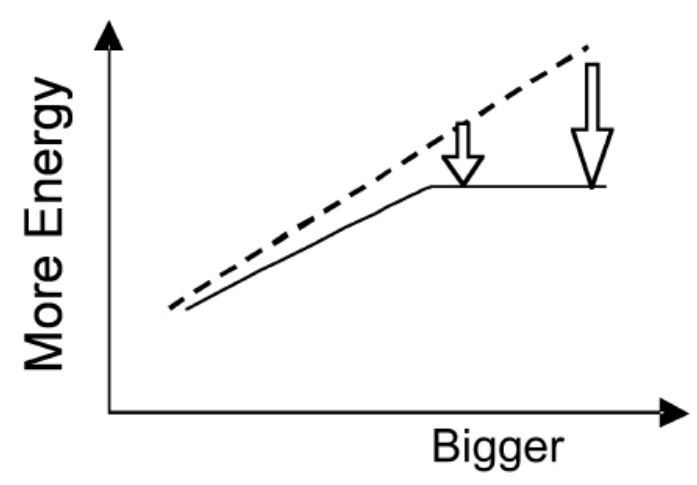

Case 4: "Sufficiency"

Case 1 shows energy efficiency remaining constant with increased scale of energy or service consumption; energy use is a linear function of size. When policy-makers want to improve energy efficiency, they tend to change the slope of that line (and perhaps the intercept) while keeping the linear relationship (Case 2). A real-world example is shown in Figure 4, below, for U.S. refrigerator efficiency standards adopted in 1993 (upper dashed lines) and then tightened significantly in 2001 (lower solid lines).

Case 3 shows our alternative formulation, with efficiency (i.e., the slope of the line) as a curve that varies with scale. Under this variable ("progressive") efficiency criterion we would expect (or require) a higher level of efficiency for a larger home or appliance. This still allows energy consumption to increase with unit size, but at a slower rate.

Case 4 shows a further variant: Above a certain size, for a very large home or appliance to be considered "efficient," it would have to offset all of its upsizing with improved energy performance, thus keeping energy consumption below a defined maximum level of consumption. Of course, it is far from obvious where to set such a maximum level, at least absent the concept of a sustainable energy balance as discussed above. 
Figure 4. Linear Efficiency for Refrigerators

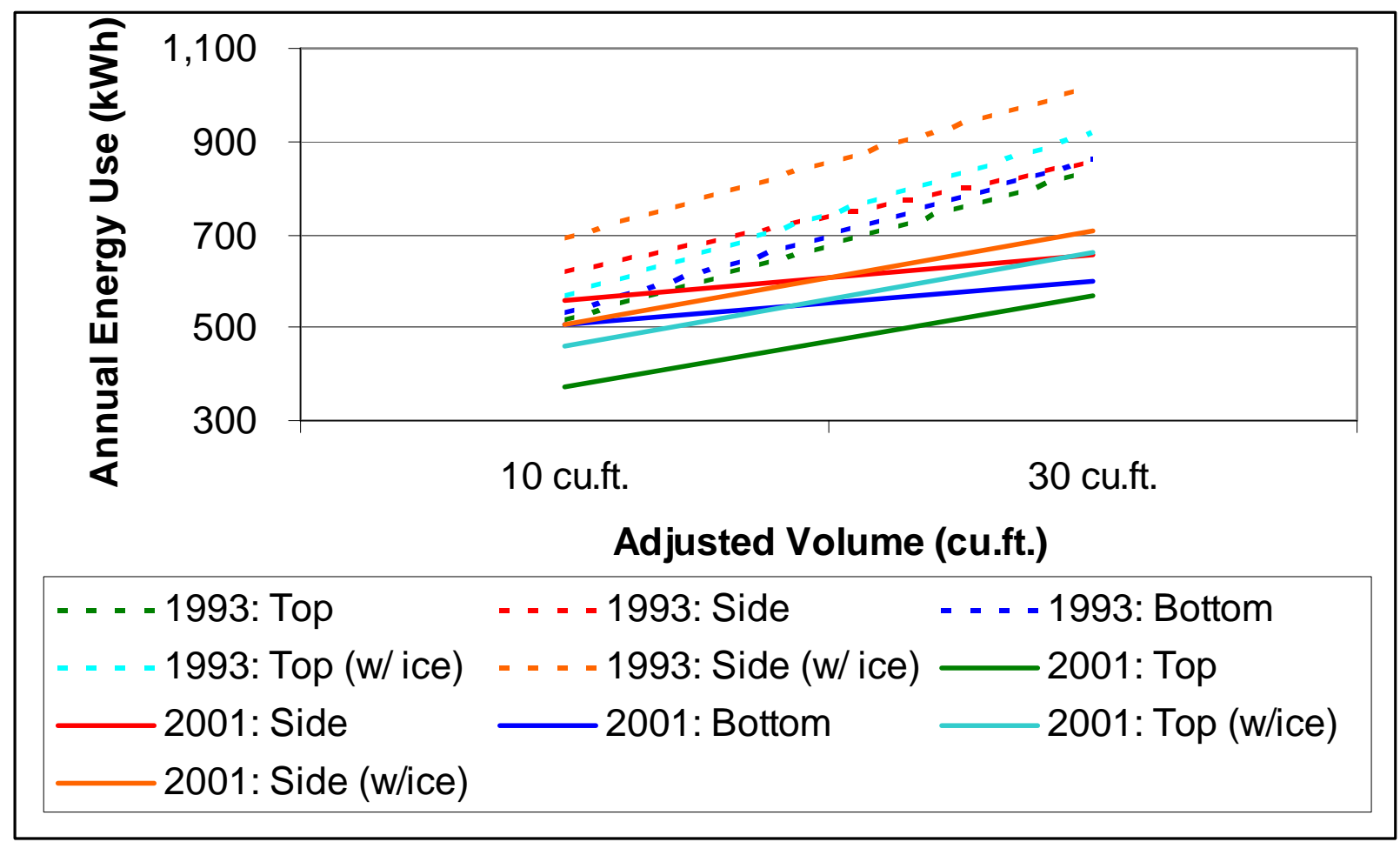

Source: U.S. Code of Federal Regulations, 2002.

\section{Illustrating the Concept through Examples}

In this section we explore some practical steps toward a policy of progressive efficiency, beginning with voluntary information and incentive programs and potentially also including mandatory standards. We offer three short illustrations of how to incorporate energy consumption along with energy efficiency: first in the choice of energy indicators, next in setting criteria for rating energy-efficient homes, and finally in the definition of categories for appliance labels (and perhaps standards) that might discourage rather than reward upsizing - or at least to help consumers make more explicit trade-offs. For these programs and others, the practice of considering energy consumption along with energy efficiency can also help energy experts, policy-makers, and the public begin to acknowledge a world of finite resources and carrying capacity, and begin to frame policy choices and public debate in terms of how best to achieve a sustainable energy balance - moving beyond assumptions of indefinite growth toward some vision of sustainable sufficiency. 


\subsection{What You Measure Is What You Get}

The debate between energy efficiency and energy conservation can be framed in terms of intensive versus extensive variables. ${ }^{1}$ Extensive variables are scale-dependent; intensive variables are not. For example, the size of the economy, as measured by gross domestic product (GDP), is an extensive variable; the energy intensity of the economy, measured by energy use per unit of GDP, is an intensive variable. For purposes of our present discussion, energy conservation and energy consumption are extensive variables; energy efficiency is an intensive variable.

For years, energy efficiency advocates have taken pains to distinguish efficiency from conservation, asserting that efficiency means providing the same service with less energy (e.g., using a more efficient furnace) while conservation means using less of a service (warming the air only to 18 or $20^{\circ} \mathrm{C}$ rather than $22^{\circ} \mathrm{C}$ ). The politics of increasing efficiency has generally been preferred - especially in the U.S. - to the politics of advocating energy conservation. Objectives are then defined in terms of intensive variables: miles/gallon, energy per square meter of floor space, electricity per ton of steel, or MJ of energy per dollar of GDP.

The current Administration has framed U.S. goals for greenhouse gas mitigation in terms of an intensive variable: tons of $\mathrm{CO}_{2}$ per dollar of GDP (White House 2002). But it is the extensive variables - carbon emissions, fossil fuel consumption, or oil imports - that should be the ultimate policy objectives. There is no a priori reason to prefer efficiency over conservation as the means to reduce energy consumption or slow its growth; the two could be combined in any proportion. Only by shifting the focus of energy policy and public debate from efficiency (intensive) to consumption (extensive), can we determine what gains are needed in energy efficiency to achieve our aspirations for economic well-being (per capita GDP), for energy services (housing, health care, leisure activities, travel); and for climate change mitigation, air quality improvement, and reduced oil dependency.

Analysts may reach different conclusions about the effectiveness of energy policies when they choose to focus on intensive rather than extensive indicators. Consider some of the trends in U.S. residential buildings, as shown in Figure 5 (and indexed to 1985). The indicator cited most often, site (delivered) energy intensity (energy per unit of floor space), declined 20\% since 1985 following an even sharper drop from 1978-85 (open diamonds in the Figure). However, in primary energy units (including electricity system losses) energy intensity declined only half as fast, or $10 \%$ from 1985 to 2002 (solid diamonds).

However, we use energy in homes to provide shelter and amenity services to people, not for the benefit of "floor space." Introducing "households" and occupants to the equation tells yet a different story. Average household size in the U.S. has been shrinking: down 3\% from 1978-85 then down another 6\% from 1985 to 2002. At the same time, the physical size of houses grew 17\% from 1985 to 2002, and this was a stock average, the average size of new homes has grown even faster. The net effect has been an increase, rather than a decrease, in per household energy use from 1985 to 2002 (up 6\%, squares in the Figure) and in energy use per occupant (up 9\%, triangles). After factoring in the 21\% population growth from 1985 to 2002 our final (extensive) indicator, total residential primary energy, increased 32\% from 1985 to 2002 after an initial decline from 1978 to 1985 (crosses).

\footnotetext{
1 The phrases "intensive variable” and "extensive variable” are more commonly used in the physical sciences than in the social sciences. For example, many thermodynamics texts discuss the distinction in an introductory chapter.
} 
So, what do the data tell us - over this period did we gain ground by $20 \%$ based on the reduction in site energy per square foot? Or fall behind by $32 \%$ based on the increase in total primary energy? Or something in between? The answer depends on the specific indicator chosen, and even more fundamentally, whether we are thinking in terms of energy consumption or energy efficiency.

Figure 5. Indices of U.S. Residential Energy

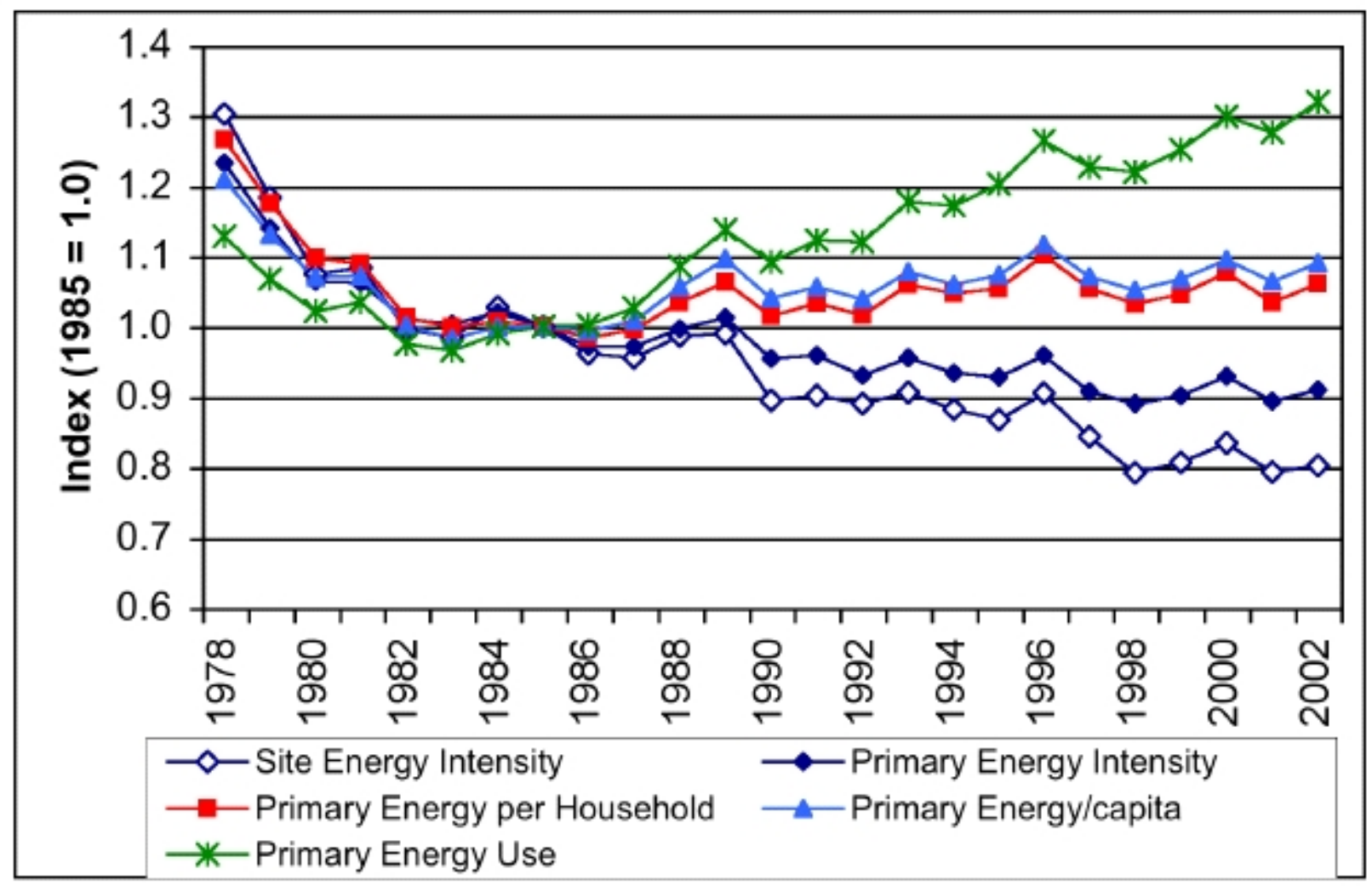

Source: PNNL 2005

Figure 6 shows a similar series of indicators for site and primary energy use in U.S. commercial buildings. Once again, the most common indicator is site (delivered) energy intensity (energy/per unit of floor space) which actually declined about 12\% from 1978 to 1985 then stayed roughly constant for the next 17 years (open diamonds in the Figure). In contrast, primary energy intensity grew by $13 \%$ over the same 17 -year period (solid diamonds). And on a per capita basis, commercial sector primary energy use per person first increased slightly from 1978-85 then more rapidly: up 25\% from 1985 to 2002 (triangles).

From one perspective it makes sense to normalize commercial energy use by the total population ultimately served by the commercial activity in offices, retail shops, health care and educational buildings, and hotels and restaurants. Another viewpoint emphasizes the "energy productivity" of commercial buildings, arguing that we are finding more efficient ways to use commercial buildings to increase GDP and to provide workspaces. The next two indicators in Figure 6 show primary energy use per employee (crosses) and primary energy per dollar of 
“adjusted” GDP (solid squares). ${ }^{2}$ Commercial sector energy per dollar of GDP declined dramatically, by more than 20\% from 1985 to 2002, while energy per employee remained roughly constant. After factoring in the growth in both GDP and commercial floor space, total primary energy use in commercial buildings - our extensive indicator - first increased about 10\% from 1978-1985 and then shot up by more than 50\% in the next 17 years (open squares).

Figure 6. Indices of U.S. Commercial Buildings Energy

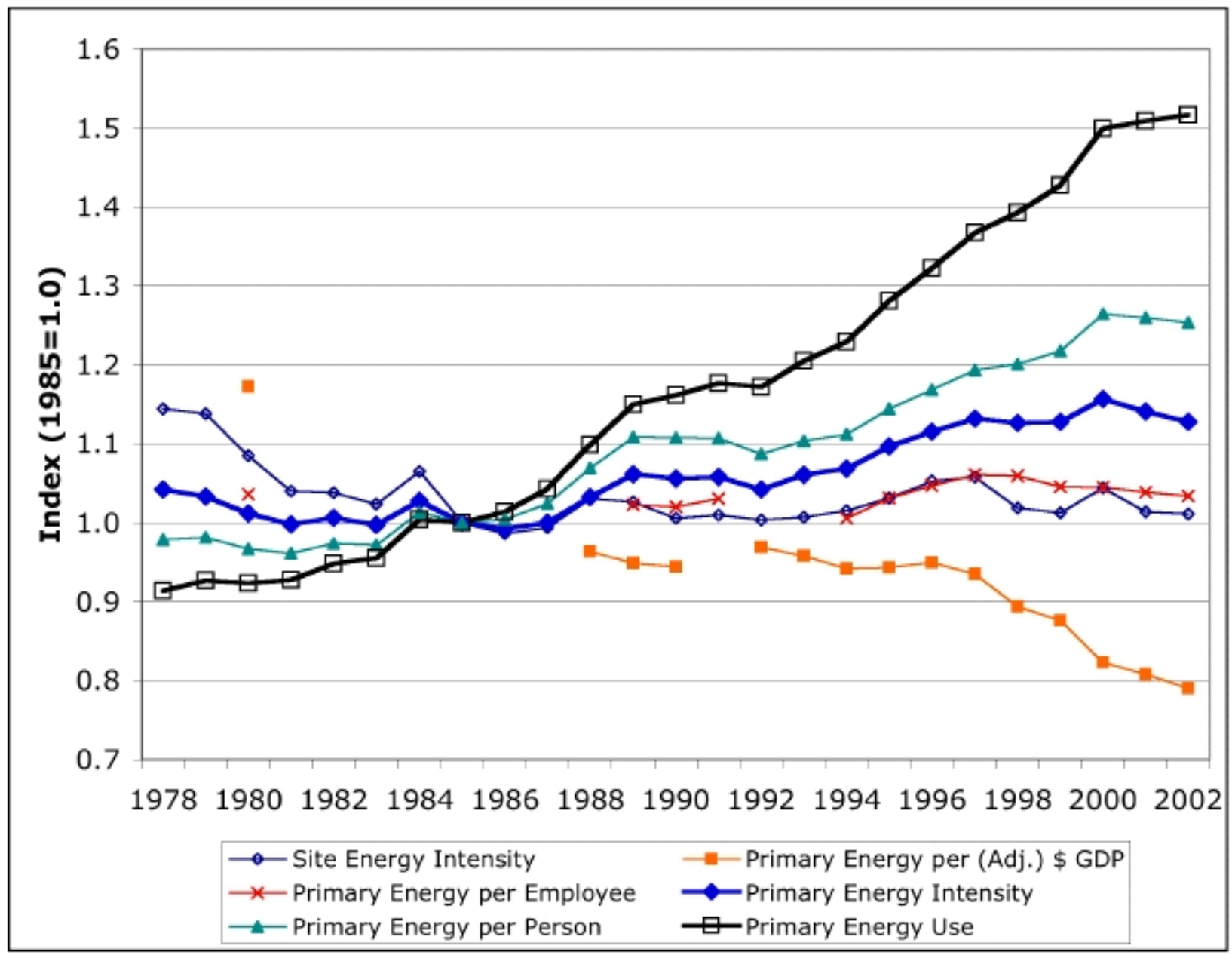

Source: PNNL 2005; Stat Abstract 1992-2006.

From these simple examples we conclude that both policy targets and tracking of progress are most meaningful when they consider multiple indicators, reflecting both energy consumption (extensive) and energy efficiency (intensive). While normalizing energy use may

${ }^{2}$ Figure 6 shows GDP in constant (2002) dollars. The data exclude GDP and employment related to manufacturing, construction, mining, and agriculture. Energy use per employee is obviously a more meaningful metric for some types of commercial buildings (offices, and perhaps retail and schools) than for warehouse or public assembly buildings with intermittent or highly varying occupancy, but a breakdown by building type was beyond the scope of this paper. Finally, a comparison of 1992 and 2003 CBECS data shows that floorspace per worker has declined in most types of commercial buildings, averaging $-7 \%$ for the sector as a whole, so the roughly constant trend in primary energy per employee is even more noteworthy. 
add useful information, the variable chosen for the denominator will significantly influence the result. If the ultimate value of using energy use is to provide services to people then energy consumption per person should always be one of the metrics we consider, along with intensive indicators of energy per unit of floor area, dollar of GDP, ton of industrial output, etc.

\subsection{Homes or Castles?}

In recent years, numerous articles and news stories in the popular press have highlighted, and often decried, the growth in average size of new U.S. homes. Increasing house size is a major factor driving growth in total residential energy and in energy per household or per capita. A second factor is the growing saturation of major appliances (more than $100 \%$ in some cases), convenience appliances, home electronics, and amenities like pools, spas, and home saunas/steam rooms. Among these trends, let us consider home upsizing in more detail.

Figure 7 shows that in 1950, the average floor area for a new house in the U.S. was $93 \mathrm{~m}^{2}$ $\left(1,000 \mathrm{ft}^{2}\right)$. By the year 2000, the average floor area for new homes had more than doubled to $204 \mathrm{~m}^{2}\left(2,200 \mathrm{ft}^{2}\right)$ (Diamond and Moezzi, 2004). Combined with fewer people per household, this growth in house size resulted in a three-fold increase in average floor area per capita, from 27 to $77 \mathrm{~m}^{2}$ (286 to $847 \mathrm{ft}^{2}$ ) per person over those five decades. In theory, bigger houses with lower surface-to-volume ratios should be more efficient in enclosing space and thus reducing heat loss and gain. In practice, though, larger houses in the U.S. tend to be less efficient per unit of floor area than smaller houses, for a number of reasons. Today's large houses often have complex perimeters (more bay windows, dormers, and other features) that add to surface area and often complicate construction detailing for insulation and air-sealing. Consequently, regardless of the code-prescribed insulation levels and air barriers, these new homes in reality may be less efficient in terms of actual surface-to-volume ratios, effective u-values, and envelope infiltration, compared with a smaller, simpler design. Larger homes also tend to have longer runs of air ducts and domestic hot water pipes, with corresponding increases in distribution losses for both HVAC and domestic hot water (DHW) systems; this loss of system efficiency is directly related to scale. Bigger houses also have more room for energy-using appliances, entertainment, and convenience devices. Finally, the higher ceilings and two-story entries and other dramatic spaces in today's new homes also increase the volume of space to be heated and cooled. ${ }^{3}$

\footnotetext{
${ }^{3}$ Even though stratification could theoretically be used in high-ceiling spaces as a strategy to reduce summer cooling requirements (while increasing them in winter), the overhead placement of air supply ducts and occupant ignorance about proper use of ceiling fans for summer comfort cooling versus winter de-stratification tend to make high ceilings a net energy penalty rather than an advantage, even in cooling-dominated climates.
} 
Figure 7. U.S. House Size (floor area) Mean and Median 1950-2000

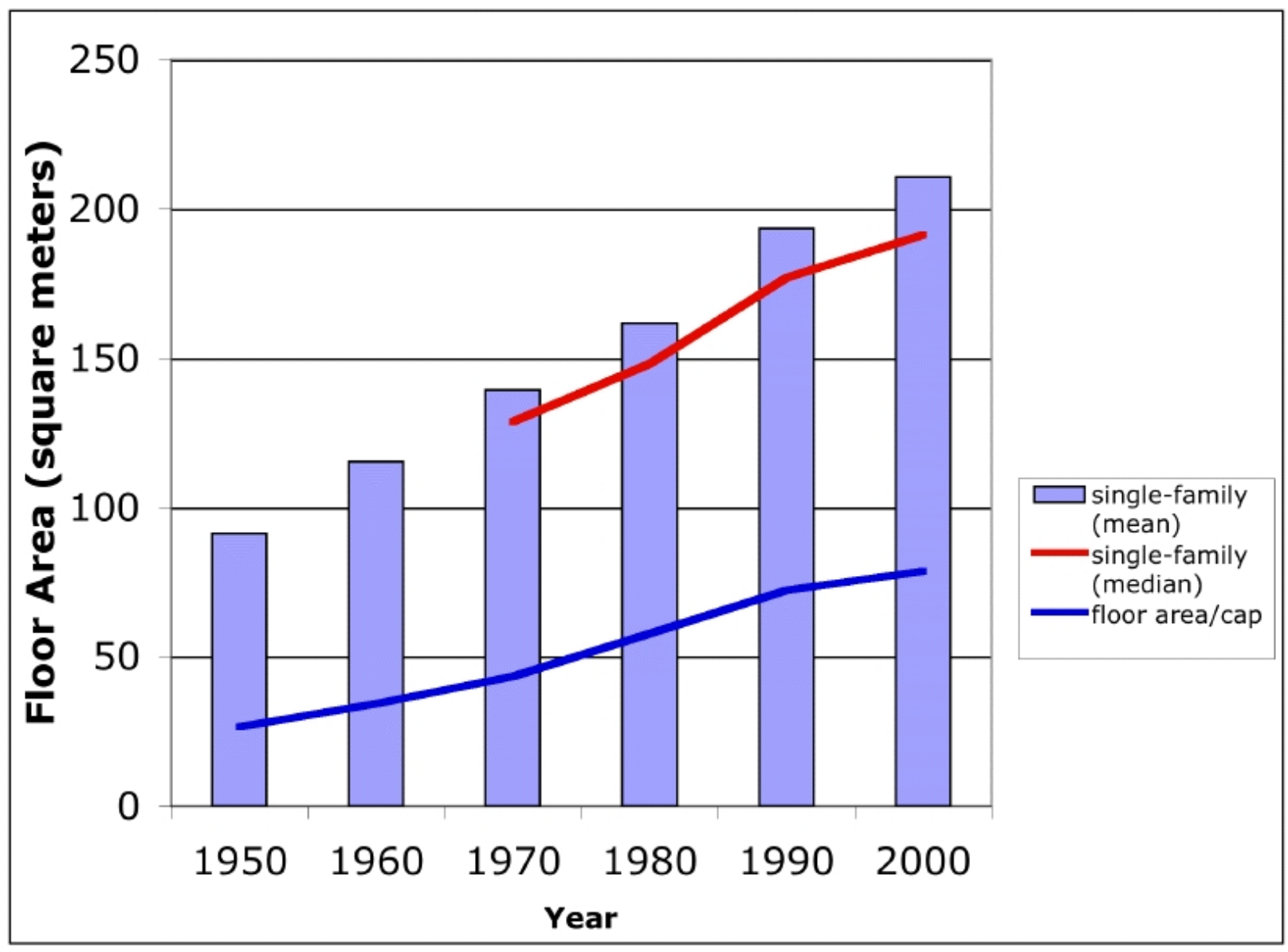

Faced with a goal of managing energy consumption towards a sustainable energy balance, we clearly need specific policies to counteract these tendencies for large houses to use more energy per unit of floor space, not less.

Perhaps we first need to better understand some of the reasons for why U.S. house size is increasing. Part of the answer may be simply that U.S. cultural norms assume that bigger is better. But in the case of housing, there may be other forces at work as well: easy mortgage loans with favorable tax treatment, zoning and real estate practices, and the expectation of continued increases in property value that encourages households to invest in housing rather than other assets. The high rate of turnover in single-family homes also contributes to a preference for larger houses, as expected resale value becomes more important in deciding the number of bedrooms and bathrooms than the actual needs (or even the desires) of the current residents. Mortgage lenders may discourage modest size homes by requiring the value of the house to be three times the value of the land. According to Art Castle, Executive Vice President of the Home Builders Association of Kitsap County, Washington: "If you put a house outside of these perimeters, you create a market aberration... A lot of lenders are unwilling to support smaller houses” (California Energy Circuit 2004).

A study by Prahl (2000) suggests that the Home Energy Rating System (HERS) used by ENERGY STAR Homes and a number of utility-sponsored programs in effect requires smaller 
houses to have higher levels of energy efficiency in order to achieve the same HERS score as a larger house. With water heating efficiency held constant, the study found that a typical $143 \mathrm{~m}^{2}$ $\left(1,537 \mathrm{ft}^{2}\right)$ home in Pittsburgh, Pennsylvania would need to install a furnace rated at $96 \%$ efficient furnace to achieve a HERS score of 86 , whereas a $517 \mathrm{~m}^{2}\left(5,564 \mathrm{ft}^{2}\right)$ house would require only an $80 \%$ efficient furnace. ${ }^{4}$

Building a bigger house to be energy-efficient will save more energy than building a smaller house at the same level of efficiency - but the larger house will still use more energy. And since smaller houses tend to be designed for the lower end of the market and sited on less expensive lots, the added energy efficiency investment becomes a larger proportion of their total purchase price. A progressive efficiency policy would call for larger homes to be not only equal in efficiency to their smaller counterparts, but to deliver proportionately more efficiency and energy savings.

Some green building rating programs have started to incorporate efficiency requirements based on house size. Like many green building programs, the Portland [Oregon] Gas and Electric certification program, Earth Advantage, combines required measures and additional points that are earned for a home's green features. In 2003, Earth Advantage created four advanced certification levels, two of which include added requirements based on house size. For example, to meet the requirements for an Earth Advantage "Gold" rating a $232 \mathrm{~m}^{2}\left(2,500 \mathrm{ft}^{2}\right)$ home needs to earn 50 more points for environmental responsibility or resource efficiency than a $186 \mathrm{~m}^{2}$ $\left(1,999 \mathrm{ft}^{2}\right)$ home (Baker 2004).

The Vermont Builds Greener (VBG) program, started in 2003 and often considered to be the most comprehensive program in the country, takes this idea one step further. To earn VBG certification, a home must meet 54 separate requirements and also earn at least 100 points. Under this system, the easiest way to qualify after meeting the minimum requirements is to build a very small house. For example, a two-bedroom house earns 100 points if it has a floor area of $93 \mathrm{~m}^{2}$ $\left(1,000 \mathrm{ft}^{2}\right)$, but only 25 points with a floor area of $139 \mathrm{~m}^{2}\left(1,500 \mathrm{ft}^{2}\right)$. Moreover, a four-bedroom house at $483 \mathrm{~m}^{2}\left(5,200 \mathrm{ft}^{2}\right)$ starts with a negative (-)100 points, meaning that other features will have to earn 200 points - twice as many - for VBG certification (Baker 2004).

The new Leadership in Energy and Environmental Design (LEED) rating for homes was introduced in 2007 by the U.S. Green Building Council (USGBC), after an extended trial period. The LEED credit for Home Size is designed to "promote the construction of homes that are smaller than the national average." Houses are penalized if they are larger than the national average for their category, based on the number of bedrooms, and get up to 10 points (out of 108 possible points) if they are smaller than average. As an example, the national average floor space for a new three-bedroom house is $176 \mathrm{~m}^{2}\left(1900 \mathrm{ft}^{2}\right)$. A house that is $269 \mathrm{~m}^{2}\left(2900 \mathrm{ft}^{2}\right)$ or larger would lose 10 points under the LEED rating, while a house under $84 \mathrm{~m}^{2}\left(900 \mathrm{ft}^{2}\right)$ would gain 10 points. Between these two extremes, a proportional number of points are added or subtracted. Realizing that the consumption of both materials and energy increases with house size the USGBC doubled the original maximum of 5 points associated with home size (USGBC 2005, p.75).

Just as some home rating systems are beginning to recognize the issue of house size and total energy use ("ecological footprint”), a small but growing number of communities are adopting local policies to discourage home super-sizing. In Colorado, Pitkin County and the

\footnotetext{
${ }^{4}$ There are a number of degrees of freedom to achieve a given HERS score. But when other parameters were varied,
} all pointed to lower efficiency requirements in the larger house. 
town of Aspen now charge new homeowners a fee if their homes exceed $464 \mathrm{~m}^{2}\left(5,000 \mathrm{ft}^{2}\right)$ and another fee up to $\$ 100,000$ if they exceed the "energy budget" for their property based on the local building code. In 2002, Marin County, north of San Francisco, California, adopted a local ordinance that new homes over $325 \mathrm{~m}^{2}\left(3,500 \mathrm{ft}^{2}\right)$ must not exceed the energy budget for a comparable $325 \mathrm{~m}^{2}$ house, and that renewable energy resources could apply to the target (County of Marin, 2002).

While these are promising developments, the country's largest energy efficiency program for new homes, ENERGY STAR for Homes, ${ }^{5}$ still allows a house of any size to qualify for the ENERGY STAR label based on a HERS rating. In July 2006, there were additional requirements that an ENERGY STAR home must include five or more ENERGY STAR qualified products, such as appliances, light fixtures, ceiling fans equipped with lighting fixtures, and/or ventilation fans. On the one hand, it is laudable that the program now considers the efficiency of these other energy uses in addition to the building envelope, space heating and cooling equipment, and hot water systems that until now have defined an ENERGY STAR new home. At the same time, these new appliance and lighting criteria may be in fact be easier to meet in a larger home which might feature two or more central air conditioners, two or more furnaces, multiple refrigerators and dishwashers, and many more ceiling fans and installed light fixtures. The program requires only five of these devices - rather than a fixed percent of the total - to be ENERGY STAR qualified, regardless of the total number of devices installed in a home. Clearly, this approach even falls short of the "linear efficiency" criterion described in Figure 3, above, instead defining "energy-efficient" in terms that are easier to meet as house size and energy consumption increase!

As we have noted, a linear criterion for energy efficiency fails to account for the thermodynamic (and marketing) opportunities to achieve greater-than-proportional energy savings in larger houses. If ENERGY STAR instead were to use the progressive efficiency approach outlined above and shown schematically in Figure 3, maximum energy consumption might be a linear function of floor area for small-to-mid size houses, while larger houses would be required to achieve steadily increasing levels of energy efficiency. And perhaps a very large home could only qualify as ENERGY STAR if it used no more total energy than a home of a specified maximum size - for example, $348 \mathrm{~m}^{2}\left(3750 \mathrm{ft}^{2}\right)$ or $50 \%$ larger than the median new U.S. home. A specification for new homes based on progressive efficiency could be further adjusted for the number of bedrooms (as some of our example programs already do) although this might further complicating compliance since the designation of a "bedrooms" could be somewhat arbitrary.

Modifying the criteria for an ENERGY STAR home based on progressive efficiency is just one example of how the concept could be applied to an important and popular program to help counter the trends toward larger homes and increased consumption. If all our policies were to take this approach, efficiency efforts could be targeted to achieve the greatest energy savings and - of direct relevance to the goals of ENERGY STAR - the largest reductions in greenhouse gas emissions.

\footnotetext{
${ }^{5}$ According to an Energy Star press release (10/05), "Currently there are more than 2,500 home builders who have constructed more than 400,000 Energy Star qualified homes, including close to 10 percent of the new housing starts in 2004.”
} 


\subsection{Categorical Illusions}

U.S. appliance energy labeling offers further examples of how to combine energy consumption and energy efficiency considerations. In this section we discuss both the Federal Trade Commission (FTC) "EnergyGuide" comparison label and the ENERGY STAR endorsement label. Both programs are based on the same appliance energy test methods adopted by DOE, and both use the same set of categories to group models for purposes of comparison. The core of the problem lies in the narrow definition of product categories. This was perhaps appropriate for their original purpose (setting mandatory national appliance efficiency standards) but it begins to pose problems when applied to labeling. Narrow categories make it difficult or impossible for consumers to compare products that might be close substitutes but use very different amounts of energy. In other words, the use of narrow labeling categories leads consumers to consider (at best) efficiency rather than consumption.

Appliance energy testing, labeling, and standards were originally authorized in the 1975 Energy Policy and Conservation Act (42USC77, Sec. 6201), at a time of intense concern over oil imports, electricity supply, and sharply higher prices for all forms of energy. Thus the Congressional statement of purpose in that law clearly includes both energy efficiency and energy conservation (reduced consumption). The labels and standards were designed:

“...to conserve energy supplies through energy conservation programs, and, where necessary, the regulation of certain energy uses [and] to provide for improved energy efficiency of motor vehicles, major appliances, and certain other consumer products...” [emphasis added]

While the efficiency of many consumer appliances has increased notably over the years, total appliance energy consumption has remained constant and in some cases has increased, due to growth in the number of appliances, their size and features, and the introduction of entirely new categories of appliances and new combinations. For example, not only do some refrigeratorfreezers offer thru-the-door-ice, water, and other chilled beverages, but some models now feature door-mounted LCD monitors connected to a TV receiver or an internet-linked PC.

As already noted, both the FTC EnergyGuide labels and the ENERGY STAR label currently compare energy efficiency within a narrowly-defined group of models with very similar size and features. As a result, the FTC labels may be shortchanging Congress's objective to help consumers make energy-conserving decisions, which would ideally involve a broader set of comparisons. In the case of refrigerator-freezer labels, for example, the narrowly defined product categories do not allow the consumer to readily compare models with similar (not identical) levels of functionality but significantly different levels of energy use. ${ }^{6}$ The effect of refrigerator size and freezer configuration on energy consumption remains largely invisible to all but the most attentive buyers.

This issue was highlighted in recent comments by the Consumers Union, as part of an FTC rulemaking on possible revisions to the EnergyGuide label:

“Consumers trying to select a refrigerator based on energy efficiency must be able to compare across categories, instead of within the current very narrowly defined

\footnotetext{
${ }^{6}$ Refrigerator-freezers are first subdivided into styles based on defrost type, freezer location and door type, and then capacity within two-cubic-foot categories.
} 
subclasses. ... The ratings of energy efficiency of refrigerators published in Consumer Reports allow consumers to directly compare refrigerators across types...” (CU 2006.)

This issue is shown graphically in Figures 8a and 8b, which compare the range of rated energy use for 16 of the most common refrigerator-freezer categories used for the FTC comparison label (four capacity ranges and four freezer configurations). Fig. 8a shows the large range of energy consumption, as a function of freezer location, among refrigerators that deliver roughly the same level of service (i.e., storage capacity). Close inspection of the data in Fig. 8a reveals that - even within these narrow size categories, the least efficient (highest-energy use) top-freezer model often uses $10-15 \%$ less energy than the most "efficient" side-by-side model with the same capacity.

These same data, regrouped in Fig. 8b, show that there is significant overlap in the range of energy use for refrigerator models with the same freezer configuration, but whose capacities differ by up to $40 \%$. Note also that, for a given freezer configuration, neither the minimum levels of energy use nor the maximum levels are (with one exception) well correlated with capacity.

In other words, grouping refrigerator-freezer models for purposes of the EnergyGuide label first by size (capacity) and then by freezer type will completely mask many of the differences to which consumers should pay attention. In particular, the energy use implications of choosing a side-by-side model are simply not communicated. In fact, the current label may lead buyers to conclude that a $\sim 700 \mathrm{~L}\left(25 \mathrm{ft}^{3}\right)$ side-by-side model using $578 \mathrm{kWh} / \mathrm{year}$ is "efficient" in an absolute sense, even though it consumes 10-30\% more energy than a top-freezer model of the same capacity. All this argues for broader categories for comparing models, making it easier for consumers to see the full range of energy use and operating costs. 
Figure 8a. Range of Refrigerator Energy Use by Capacity (Adjusted Volume in $\mathrm{ft}^{3}$ )
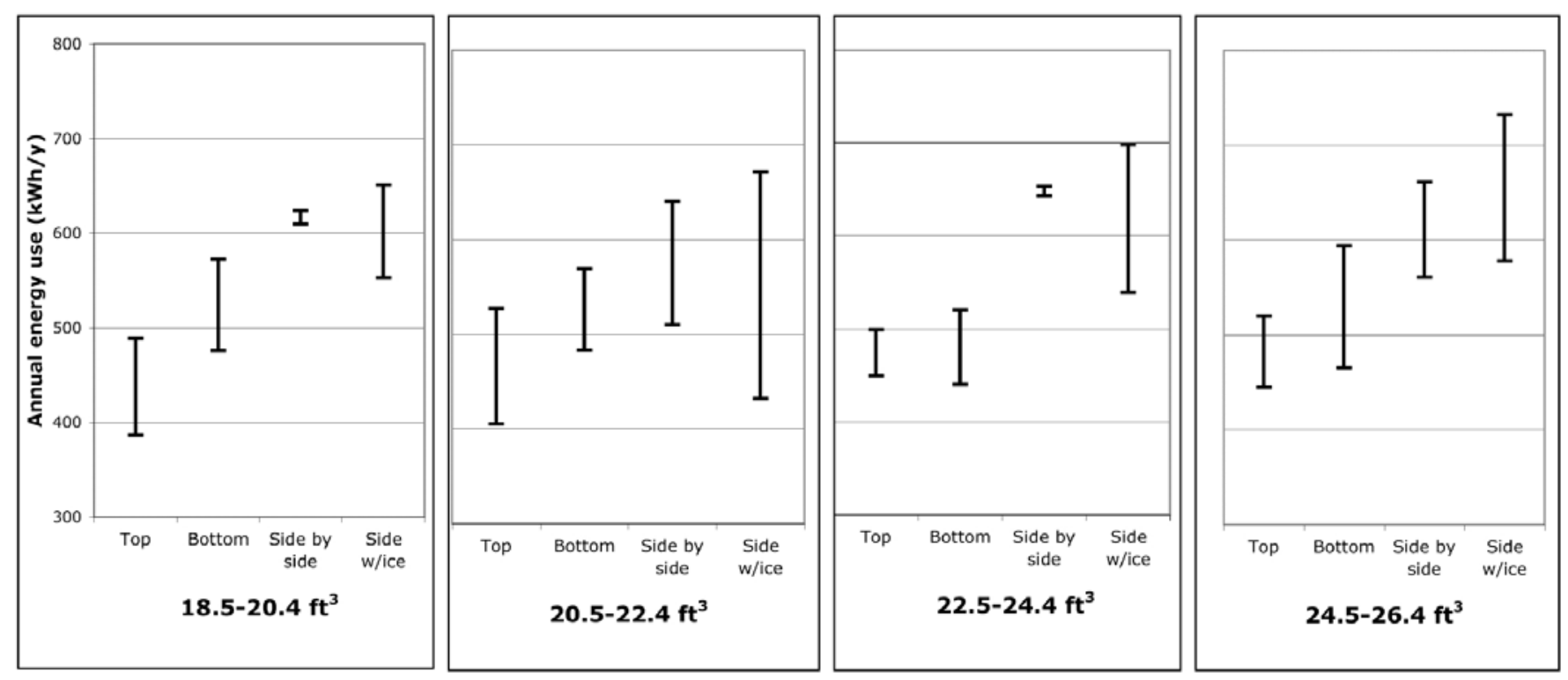

Figure 8b. Range of Refrigerator Energy Use by Freezer Location
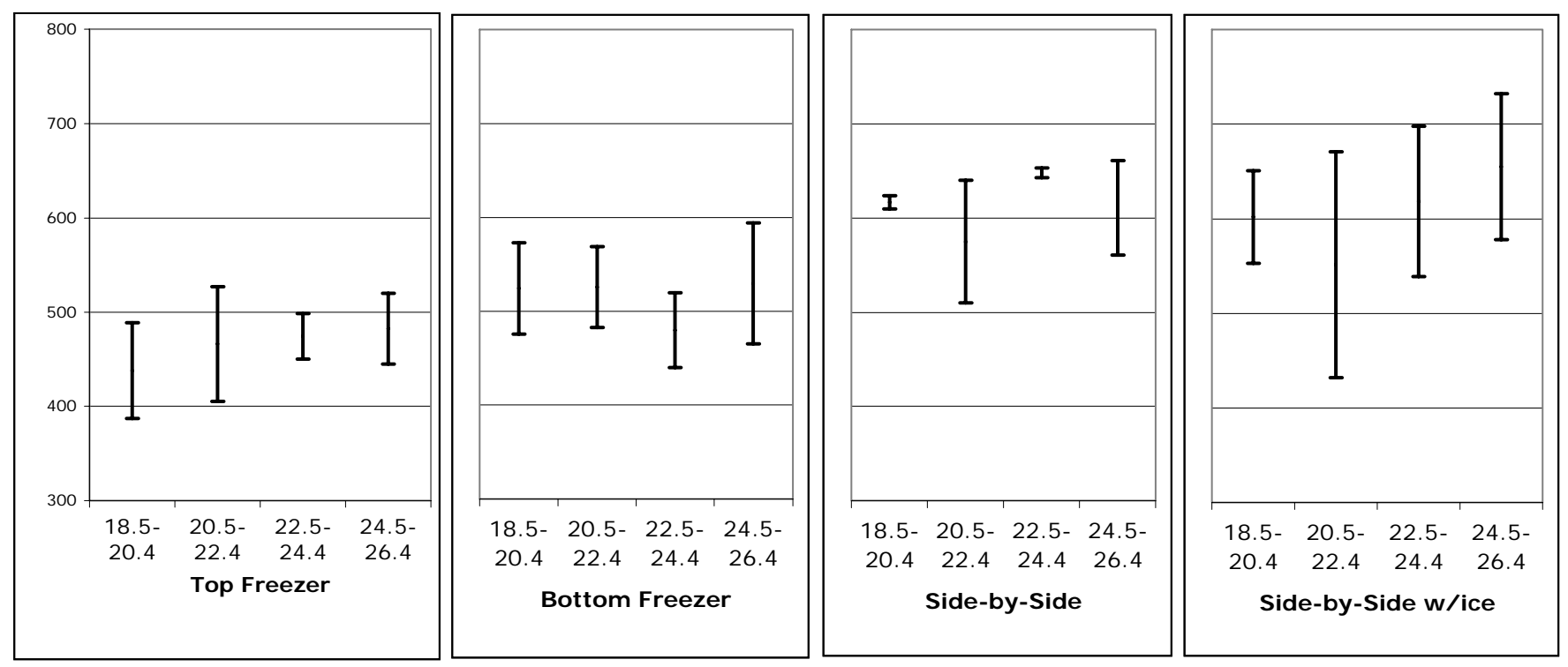

Source: FTC 2006.

In contrast, the EnergyGuide label for clothes washers was changed a few years ago to include within a single comparison group both the newer horizontal-axis models and the conventional vertical-axis models. Prior to that change, horizontal-axis washers were placed in a separate category for purposes of labeling, even though there was relatively little difference in energy use between the most efficient and least efficient horizontal-axis models - but large 
differences in both energy and water consumption between any horizontal-axis washer and any vertical-axis model. With this consolidation of the two categories, the FTC label now allows consumers to compare energy performance across the full range of clothes washer models. The current range of energy use is about 6:1, and even after normalizing for washer tub capacity, the energy performance range is more than $5: 1^{7}$

Many of the same issues with defining appliance categories too narrowly also apply to the ENERGY STAR endorsement label. These narrow categories emphasize energy efficiency more than energy consumption. Once again, to quote the Consumers Union critique:

“...[W]e believe that the current method of determining EnergyStar designations is deeply flawed. A specific example of this flawed application in the labeling of EnergyStar refrigerators is highlighted in the following example:

Assume that the consumer is going to buy a refrigerator with $227 \mathrm{~L}\left(8 \mathrm{ft}^{3}\right)$ of freezer space, and $396 \mathrm{~L}\left(14 \mathrm{ft}^{3}\right)$ of fresh food space.

- Under regulations effective July 1, 2001 a refrigerator/freezer with the above specifications configured with the freezer on top would be allowed to use 541 $\mathrm{kWh} / \mathrm{yr}$;

- A top freezer that actually used $466 \mathrm{kWh} / \mathrm{yr}$ (14\% less than allowed) would not be labeled as an EnergyStar model;

- A side-by-side model that used $578 \mathrm{kWh} / \mathrm{yr}$ (15\% less than that allowed for side-bysides) would be labeled as an EnergyStar model.

- A refrigerator configured as a side-by-side model with ice- and water-dispensers would be allowed to use $679 \mathrm{kWh} / \mathrm{yr}$ and still retain an EnergyStar designation.

"Thus, a model using $112 \mathrm{kWh} / \mathrm{yr}$ (24\%) more than another would be labeled EnergyStar while the model with greater actual energy efficiency would not.” (CU 2006)

For labels to be effective at helping consumers reduce energy consumption, the energy use comparisons need to cover a broader range of comparable products, not just nearly-identical ones. Consumers will then be able to discern truly informed trade-offs between product size, features, and first cost on the one hand, and energy consumption (and operating costs) on the other. And, for appliances as for houses, endorsement labels like ENERGY STAR should consider adopting progressive efficiency criteria that require larger models to deliver proportionately higher levels of energy performance and savings.

\section{Toward a Policy of Variable Efficiency}

In the preceding pages we discussed the reasons why energy consumption, rather than energy efficiency, should be the main focus of energy policy in a resource-constrained and carbon-burdened world. We suggested that the concept of sustainable energy balance provides a framework for both energy efficiency and energy conservation. The choice is not between pursuing energy efficiency or advocating energy conservation; both have a role to play in

\footnotetext{
${ }^{7}$ The actual range of FTC-reported clothes washer data is even larger; the ratios cited here are based on eliminating a few outliers which may represent reporting or recording errors.
} 
managing energy consumption and its consequences. Energy efficiency is often the most attractive way to slow and possibly reverse growth in energy demand. And while energy conservation does not always involve sacrifice, as implied by President Carter's sweater, in some cases it may. In that regard, energy consumption is similar to other important personal and societal goals that sometimes call for sacrifice: sending our children to college, caring for an aging parent, or countering terrorism. The question is how much sacrifice is avoidable, how much is necessary, and how much we are willing to accept. Slowing growth in energy consumption can mean real sacrifice for many in the developing world who still await access to electricity or clean water. But for most of us fortunate enough to live in the U.S. or other industrial countries, a great deal of conserving can result from only a modest shift in our aspirations. The question is whether we can learn to be satisfied with sufficiency rather than pursuing excess, in the form of oversized houses, cars, and fleets of household devices for our convenience and entertainment.

There are many difficulties - conceptual, practical, and ethical - in proposing a transition from unbounded consumption to comfortable sufficiency. Many will disagree on the necessity or merits of doing so. Rather than press the point in this paper, we have proposed that the concept of progressive efficiency be built into energy policy and program design. We believe that progressive efficiency represents a useful and politically feasible first step to help us manage energy consumption in response to oil, climate, and grid constraints. Considerations of both thermodynamics and equity argue for energy-efficiency requirements that vary with scale. Starting with information and endorsement programs like home energy rating and appliance energy labels, we can begin to educate both consumers and policy-makers that in the case of energy use, "size matters." Once the principle of progressive efficiency is embedded in voluntary information and incentive programs, policymakers and program sponsors can consider how to extend the concept to mandatory codes and standards. This is easier to envision for appliances and homes; it is admittedly more of a challenge to apply progressive efficiency in the case of offices, retail space, health care, or industrial processes. Finally, energy indicators should include both extensive variables (consumption) as well as intensive ones (efficiency or productivity). Consumption-based indicators can be used to calibrate policy goals, helping us decide how much we need to increase efficiency and when we need to move beyond efficiency in order to assure a sustainable energy future.

\section{Acknowledgements}

The authors would like to thank our colleagues Kathryn Janda and Alan Meier who provided thoughtful review comments on earlier versions of this paper, and our two anonymous reviewers who added enormous value in clarifying our arguments.

This work was funded by the U.S. Department of Energy under Contract No. DE-AC0205CH11231, and the California Energy Commission's Public Interest Energy Research Program. The views expressed in this paper are solely the views of the authors, and not necessarily those of the funding institutions. 


\section{References}

Baker, L.. (2004, July). “Great big green monster mansions.” Salon.com July 7, 2004. Retrieved August 20, 2004 from http://archive.salon.com/tech/feature/2004/07/07/green_big_houses/index.html.

Binswinger, M. (2001). Technological progress and sustainable development: what about the rebound effect? Ecological Economics 36 (1), 119-132.

Birol, F., and Keppler, J. H. (2000). "Prices, technological development and the rebound effect." Energy Policy. 28 (6/7), 425-432.

California Energy Circuit. (2004, August 13). "Livin' large causes demand to surge in Inland Empire.” Retrieved August 20, 2004 from . http://www.californiaenergycircuit.net/

City of Aspen, Colorado. (2002). Adoption of the 1999 Aspen/Pitkin Energy Conservation Code, as Amendments to the City Building Code, Section 8.20.020. Retrieved September 20, 2004 from http://www.bpcnet.com/codes/aspen/_DATA/Title_8/20/020.html

Consumers Union. (2006). Comments of Consumers Union of the US, Inc. to the Federal Trade Commission “Energy Labeling, Project No. R511994” 16 C.F.R. Part 305. Washington DC. Jan. 13. Retrieved March 10, 2006 from http://www.ftc.gov/os/comments/energylabeling/51987000017.pdf

County of Marin [California]. (2002). "Single Family Dwelling Energy Efficiency Ordinance-Marin County, California.” Retrieved September 20, 2004 from http://www.co.marin.ca.us/EFiles/BS/AgMn/02_1022/html/Item-17-ord.pdf

Diamond, R. and Moezzi, M. (2004). "Changing trends: A brief history of the U.S. consumption of energy, water, beverage and tobacco," published in the Proceedings of the 2004 Summer Study on Energy Efficiency in Buildings, American Council for an Energy Efficient Economy, Washington DC, August, 2004.

Energy Design Update. (March 2003). “Grappling with national green standards.” Energy Design Update 23 (3).

Herring, H.. (2006). “Energy efficiency-A critical view.” Energy 31 (1): 10-20.

Howarth, R. B., (1997). "Energy efficiency and economic growth.” Contemporary Economic Policy. XV (4), 1-9.

Greening, L.A., Greene, D.L., Difiglio, C.. (2000). "Energy efficiency and consumption-the rebound effect—a survey,” Energy Policy, 2000. 
Meier, A. (2000). “Living in a carbon constrained world,” Home Energy, March/April 2000.

Moezzi, M. (1998). “The predicament of efficiency.” Proceedings of the 1998 ACEEE Summer Study on Energy Efficiency in Buildings. Washington DC: ACEEE.

Moezzi, M. and Diamond, R. (2005). "Is efficiency enough? Towards a new framework for carbon savings in the California residential sector." California Energy Commission PIER report, Sacramento, California. LBNL Report-58580.

National Association of Home Builders . (2003). "Housing facts: Figures and trends 2003." Washington, DC.

Prahl, D.. (2000). “Analysis of energy consumption, rating score, and house size.” Washington D.C.: U.S. Green Building Council.

Pacific Northwest National Laboratories . (2005). "Indicators of energy intensity in the United States.” Retrieved March 10, 2006 from http://intensityindicators.pnl.gov/

Princen, T. (2005). The Logic of Sufficiency. Cambridge, MIT Press.

Rudin, A. (2000). "Why we should change our message from 'Use energy efficiently' to 'Use less energy'." Proceedings of the 2000 ACEEE Summer Study on Energy Efficiency in Buildings. Washington DC: ACEEE.

Siderius, H-P. (2004). "The end of energy efficiency improvements = The start of energy savings?!” Proceedings of the 2004 ACEEE Summer Study on Energy Efficiency in Buildings. Washington DC: ACEEE.

U.S. Code of Federal Regulations, (2002). Energy Conservation Program for Consumer Products. 10CFR430 - PART 430. Retrieved March 20, 2004 from http://www.access.gpo.gov/nara/cfr/waisidx_02/10cfr430_02.html

U.S. Department of Commerce, Bureau of the Census. (2006). "US Statistical Abstract." Retrieved March 20, 2006 from http://www.census.gov/statab/www/

U.S. Department of Energy, Energy Information Administration. (2004a). Annual Energy Review. “Table 2.1a Energy Consumption by Sector, Selected Years, 1949-2004.” Retrieved March 20, 2006 from http://www.eia.doe.gov/emeu/aer/pdf/pages/sec2_4.pdf

U.S. Department of Energy, Energy Information Administration. (2004b). "Annual Energy Outlook 2004 with Projections to 2025. U.S. Department of Energy.” DOE/EIA-0383(2004). Retrieved March 20, 2006 from www.eia.doe.gov/emeu/aer 
U.S. Federal Trade Commission . (2006). Appliance energy data. Listings for refrigerators and

freezers as of May 1, 1006. Retrieved March 20, 2006 from http://www.ftc.gov/appliancedata

U.S. Green Building Council. (2005). "Rating system for pilot demonstration of LEED for Homes Program. Version 1.72.

Retrieved March 20, 2006 from

http://www.usgbc.org/DisplayPage.aspx?CMSPageID=147

White House. (2002, February). “Global change policy book.” Washington, DC. Retrieved March 20, 2006 from

http://www.whitehouse.gov/news/releases/2002/02/climatechange.html

Wilhite, H., Lutzenhiser, L., Shove, E. and Kempton, W.. (2000). "Twenty years of energy demand management: We know more about behavior but how much do we know about demand?” Proceedings of the 2000 ACEEE Summer Study on Energy Efficiency in Buildings. Washington DC: ACEEE.

Wilhite H. and Norgard J.S. (2004). "Equating efficiency with reduction: A self-deception in energy policy.” Energy \& Environment, Volume 15, Number 6, November 2004 , pp. 991-1009 (19) 